\title{
Gombrich, una mente lúcida
}

\author{
por \\ JUANA GUTIÉRREZ HACES \\ Instituto de Investigaciones Estéticas, unAM
}

Tolto dunque un uovo, tutti que'maestri si provarono per farlo star ritto, ma nessuno trovó il modo. O nde essendo detto a Filippo che lo fermasse, egli con grazzia lo prese, e datogli un colpo del culo in sul piano del marmo, lo fece star ritto. Romoreggiando gli artefici, che similmente arebbono ancora saputo voltare la cupola, vedendo il modello o il disegno.

Vida de Brunelleschi. Vasari, Le vite...

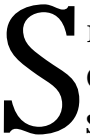

I ha habido entre los historiadores del arte uno que supo reconocer sus deudas, ése ha sido Ernst H. Gombrich. Tan sólo con nombrar su libro Tributos. Versión cultural de nuestras tradiciones sería suficiente, pero en cualquier artículo o libro, conferencia o curso estuvo dispuesto a reconocer y declarar de dónde venían sus ideas. Nunca estuvo casado con la necesidad de originalidad que nos ha vendido la modernidad. Él sabía que retomar un tema, o desarrollar una idea con base en los que nos preceden 0 incluso en nuestros coetáneos, era rendir homenaje a la madre del Progreso, la Tradición, y de esa manera sin pretenderlo siempre fue original.

Gustó siempre de escribir con llaneza fuera el tema que fuera, por eso sus ideas por novedosas o difíciles que sean siempre tienen el mérito de ser no sólo comprensibles, sino de adquirir un aire de cotidianidad, de ya sabido, que engaña al más hábil lector. Parte de su éxito editorial, y por qué no, académico, es esa sensación que dejan sus escritos de que aquello que se dice siempre había estado allí y, a veces, de que casi era obvio, que sólo tenía que venir una mano que retirara el velo para que todo se aclarara, y él fue la mano que recorrió el velo en tantos y tantos temas. La mezcla de llaneza para
\end{abstract}

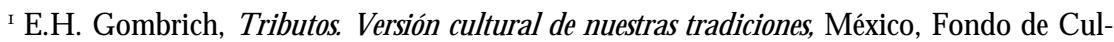
tura E conómica, I99I. 
explicar sus ideas con el factor sorpresa, que él mismo estudió como un componente exitoso para la asimilación de nuevas ideas artísticas, logró que sus escritos nunca dejasen en el lector una huella de superioridad o pedantería, y esto no es poco decir cuando se maneja, como Gombrich, una cultura amplia y erudita.

Escribir algo para rendir homenaje a una personalidad como Gombrich siempre es difícil, sobre todo ante la extensión de su obra y la variedad de temas que tocó, aunque se podría decir que hay preocupaciones constantes. Pero la dificultad mayor es saber hacer lo que él supo hacer de forma magnífica, es decir, este tipo de reconocimientos, este género conmemorativo. Alguien debería añadir como epílogo de su libro Tributos uno dedicado a él, en la conciencia de que con eso se cerraría un círculo de deudas, pero no sólo eso, se completaría, a la manera del Studiolo de Federico de M ontefeltro, no sólo una galería de retratos sino la visión de una estructura disciplinaria que él colaboró a crear. Atinadamente el título que le pusieron a esta obra en italiano fue una frase que el mismo Gombrich utilizó: "custodios de la memoria" y Gombrich lo fue hasta el final de su vida.

Ante esta dificultad, pero también ante las características ya anotadas del carácter sencillo de sus explicaciones, he empezado con un pasaje de la vida de Filippo Brunelleschi, quizá uno de los más famosos, no sólo como una manera de rendir homenaje a un estudioso del Renacimiento, sino porque creo que los que hemos leído y estudiado a Gombrich alguna vez hemos tenido la tentación de decir, como los maestros de la O pera del Duomo de Florencia: ¡Ah, desde luego, así tiene que ser! Pero lejos de una actitud mezquina como la de los florentinos, uno no cabe de asombro al constatar que esas respuestas y explicaciones, que a primera vista parecen obvias, nacen de una mente perfectamente estructurada, imaginativa y alejada de toda complicación innecesaria, y una mente, además, ferviente creyente de la explicación científica, pero también de la limitación que aún hoy enfrenta el historiador del arte, y no sólo por los caminos de la percepción que siguió Gombrich, sino muchos otros. Estas limitaciones que enfrenta el estudioso de las imágenes se describen perfectamente con la anécdota que cuenta Gombrich de cuando conoció a Wolfgang Köhler, teórico de la G estalt, en la cual narra que le dibujó sobre el pizarrón "un rostro simplificado, como los que hacen los niños: un redondel con dos puntos para los ojos, una raya para la nariz y una raya para la boca. $Y$ preguntó: ' $Q$ uiero descubrir lo que ocurre cuando reconocemos un rostro de un dibujo semejante'. Köhler respondió: 
'D emasiado complicado. La psicología está aún en pañales, todavía no hemos llegado a esa fase'." ${ }^{2}$ Gombrich lo entendió, aún es demasiado pronto para que entendamos tantos misterios, pero no dejó de cooperar para que llegue el día y no dejó tampoco de descubrir a tantos lo que ya se sabe.

Podríamos decir que las hipótesis que apoyó las aplicó fielmente no sólo a los objetos de estudio sino a su forma de ser historiador del arte, no sé si consciente 0 inconscientemente, baste para probarlo su descripción de historia del arte que hace al finalizar su libro Arte e ilusión: "la historia del arte... puede describirse como forja de llaves maestras para abrir las misteriosas cerraduras de nuestros sentidos, de las que en el origen solamente la naturaleza tenía la llave. Son cerraduras complejas que sólo responden cuando varios tornillos están en cierta posición y algunos pestillos se mueven al mismo tiempo. Como el ladrón que trata de abrir una caja fuerte, el artista no tiene acceso directo al mecanismo interior. Sólo puede palpar el camino con dedos sensibles, tanteando y ajustando su gancho 0 alambre cuando algo cede. Claro, una vez que la puerta se abre, una vez que la llave está moldeada, es fácil repetir la ejecución. La siguiente persona no requiere talento especial; es decir no más del necesario para copiar la llave maestra de su predecesor."3 Aquí G ombrich siendo fiel a sus ideas sólo "describe" lo que es la H istoria del Arte alejándose de las definiciones que tanto rechazaba por los esencialismos implícitos en ellas, habla de tanteos, de la misma forma que describió el avance del arte y los artistas a través de ensayo y rectificación, esquema y corrección. También al hablar de los que siguen el camino iniciado por otros, se liga a sus explicaciones sobre la tradición y las convenciones, porque sabía como él mismo dice que: "allí donde los problemas no se plantean por parte de la comunidad, se plantean por parte de la tradición".4 Lo que trato de decir es que no sólo aplicó a la historia de la "creación de imágenes" sus hipótesis, sino también a la forma en la que él se conducía al hacer la historia de las imágenes, él también seguía la tradición, él también avanzaba con "tanteos", él también era "testigo ocular", él también era absolutamente consciente de su individualidad como creador de hipótesis y no el producto de un "espíritu de los tiempos", él también sabía que sus escritos se daban porque eran "ecoló-

${ }^{2}$ Ernst G ombrich-D idier Eribon, Lo que nos cuentan las imágenes, M adrid, Editorial D ebate, Pensamiento, 1992, p. 96.

3 E.H . G ombrich, Artee ilusión, Barcelona, Gustavo Gili, 1979, p. 310.

${ }_{4} \mathrm{G}$ ombrich-Eribon, op. cit., p. 62. 
gicos" y había condiciones para que "se dieran"; él también sabía que, como el lenguaje es el creador, él sólo era, como el poeta o el pintor en sus tareas, un misterioso vehículo para hacer la historia de la creación de imágenes.5

Lo interesante, por tanto, es que lo que decía de los fenómenos artísticos lo aplicaba a su forma de hacer historia, porque creía en ello, y no siempre es común encontrar a un estudioso que presente tal coherencia vital. Por todo la anterior los escritos de Gombrich son profundamente educativos y no estoy hablando sólo por su efecto en los estudiantes, sino en todos los que nos dedicamos a la $\mathrm{H}$ istoria del Arte. Un estudiante, impresionado por la cantidad y dificultad que afronta el estudio de la $\mathrm{H}$ istoria del Arte, se encuentra reconfortado, al igual que el más experimentado investigador, al ver que a lo largo de su obra Gombrich siempre se hace preguntas abiertamente, expresa sus dudas y dificultades y de ahí sal ta a hipótesis y explicaciones que siempre son clarificadoras, yo diría aleccionadoras, jamás pontifica, asume por el contrario la postura del experimentador constante, y eso siempre da seguridad a cualquiera que se inicia en la $\mathrm{H}$ istoria del Arte, así como al que, ya avezado en estas tareas, está por iniciar cualquier investigación.

G ombrich siempre trabajó haciéndose preguntas a las que siempre les encuentro explicaciones, y no hay nada más educativo que esto, ya que uno puede observar las entrañas y la evolución de un trabajo hasta llegar a la conclusión. Por esta razón sus preguntas y respuestas son aplicables, incluso, a los temas más al ejados de las áreas artísticas que él explicaba, porque las convierte en ideas generales. Gombrich deseó siempre avanzar sobre este terreno y no sobre el de los particularismos, creía que en una investigación se deberían, sí, estudiar las minucias y desde luego los detalles que caracterizaban a las obras, pero se debía avanzar sobre ideas generales, de ahí que las que creó Gombrich puedan utilizarse en un amplio espectro de la historia del arte y no sólo en ella. ${ }^{6}$

5 E.H . G ombrich, "La necesidad de la Tradición. Interpretación de la poética de I.A. Richards (I893-1979)", en E.H. Gombrich, Tributos. Versión cultural de nuestras tradiciones, reimpresión, M éxico, Fondo de Cultura Económica, 1993, pp. I8I-I95I. A partir de I. Richards, invierte el veredicto de Croce y, como dice, atribuye la responsabilidad de componer poesía al lenguaje, no al intelecto, sentimiento o sabiduría del poeta.

${ }^{6}$ E.H. Gombrich, "Arte y saber histórico", en M editaciones sobre un caballo de juguete, Barcelona, Seix Barral, Biblioteca Breve, M useo Extraordinario, I968, p. I43-I44. T ambién en la entrevista G ombrich-Eribon, op. cit., avanza sobre esto que tantas veces sacó a colación en sus artículos y conferencias diciendo: "M e sentía un poco molesto de leer tantas cosas sobre los 
Su actitud flexible frente a la adquisición del conocimiento es también educadora porque rechaza la imagen del sabio aislado y se convierte en el siempre atento aprendiz de otras áreas del conocimiento, que pueden ir desde el comportamiento animal, la física, la ingeniería o la lingüística, etc. Pero sobre todo, lo importante es que nos demuestra que está en una permanente disposición de cambiar. Como ejemplo está el pasaje de la entrevista donde explica cómo fueron cambiando sus ideas en aspectos básicos para la comprensión de las imágenes y no sólo eso, de ahí parte para dar conceptos nuevos e interesantes para la reflexión sobre el arte. Partiendo del supuesto de que la visión depende del conocimiento, cuenta que: "Al principio mi idea era en realidad 'de saber a ver'. D el conocimiento a la visión. Gracias a Popper, me di cuenta de que 'conocimiento' no es la palabra adecuada: es una espera, una hipótesis. La hipótesis puede ser cierta o falsa. Lo que influye en un artista cuando mira no es que sepa... sino que supone, modifiqué pues poco a poco mi concepción: un cuadro es una hipótesis que ponemos a prueba al mirarla... Yo no me pregunto cómo vemos el mundo, sino como vemos los cuadros... N o vemos el mundo como imagen plana. Pero curiosamente, vemos un cuadro como si fuera el mundo... "7 Este párrafo es de suma importancia para el historiador del arte y para el que esté interesado en las imágenes, pues nos hace conscientes del punto de partida de todo aquel que hace historia del proceso de la creación de las imágenes, esto es, el cuadro mismo, la imagen misma. Actualmente las imágenes han ido cobrando un interés particular en los estudiosos de áreas académicas vecinas que desde luego enriquecen nuestra visión, y nada más alejado de nuestra intención es negar su importancia, porque estaríamos cayendo en aquello que Warburg y el mismo Gombrich Ilamaron "guardias fronterizos", que son aquellos que celosamente no quieren que ningún área del conocimiento se mezcle 0 avance sobre otra. La de Gombrich, como fiel partícipe del Instituto Warburg,

detalles y nada sobre los problemas generales. Sigo pensando que nos faltan ideas generales en nuestras asignaturas. $\mathrm{N}$ aturalmente, esta insistencia en las ideas generales, procede, como lo he dicho, de la historia del arte alemana y austriaca. N o es invención mía. Los ingleses son de naturaleza más positiva. Les gusta ir a los detalles y, tras esa gran moda de la iconología, han vuelto sus investigaciones puntillistas, sin segundos planos filosóficos. Por mi parte yo repre sento aún a esa vieja tradición que piensa que no se pueden plantear nuevas preguntas intere santes sin tener en mente los problemas generales", p. I46.

7 G ombrich-Eribon, op. cit., p. 8o. H ablando de su libro Artee ilusión. 
fue una vida consagrada a derribar las barreras convencionales entre las Ilamadas "especialidades" de estudio. ${ }^{8}$ Lejos de esta posición, sí cabe aclarar que muchos de los que hoy se acercan a las imágenes olvidan lo que Gombrich nos recuerda: lo que vemos son cuadros y cuando se observa un cuadro se realiza una percepción de las imágenes y no la percepción de la realidad. Los historiadores y aun los iconógrafos piensan que perciben una realidad histórica cuando usan imágenes, pero en realidad lo que perciben es la realidad de las imágenes y mientras no estén conscientes de ello estarán escribiendo una falacia. Como dice Gombrich: "nuestra imaginación tiende a transformar lo que vemos en realidad y difícilmente, semejante proyección, no puede suprimirse completamente o separarse de los elementos brutos de la visión... "9 D espués añade que en el fondo se trata del papel que nuestras "estimaciones" juegan en nuestras percepciones. Por lo tanto deberá tenerse en cuenta que lo que percibimos de un cuadro es una estimación, la visión de un cuadro es una hipótesis.

En su famoso ensayo "M editaciones sobre un caballo de juguete", ${ }^{\text {ro }}$ Gombrich abre una puerta para descender de la reflexión filosófica a una aplicación práctica que da esperanzas sobre la utilización de estas ideas. Esto es congruente con lo que él pensaba, ya que siempre desconfió de la estética, pues como decía, no sé si me están hablando del arte egipcio o de una pintura de Velázquez, por eso dice: “Creo que debe establecerse una distinción muy importante entre aquello de lo que estamos seguros y lo que podemos creer 0 aquello sobre lo que podemos establecer una hipótesis. Podemos establecer una hipótesis sobre lo que M iguel Ángel quería hacer, pero no podre mos tener jamás una certeza total. Lo más a menudo, está unido a lo que Popper llama la 'lógica de la situación'. Si se sabe que se puede reconstruir lo que era la situación, se puede reconstruir también cómo una persona razonable ha reaccionado ante la situación. $\mathrm{H}$ ay muchos ejemplos donde se puede estar bastante seguro, donde se puede encontrar las intenciones por comparación y la reconstrucción de la situación en la que se encontró al artista."II

${ }^{8}$ E.H. Gombrich, "Prefacio" en M editaciones sobre un caballo de juguete, Barcelona, Seix Barral, Biblioteca Breve, M useo Extraordinario, i968, p. го.

${ }_{9}$ Gombrich-E ribon, op. cit., p. 82.

ro "M editaciones sobre un caballo de juguete. 0 las raíces de la forma artística en Gombrich", M editaciones... op. cit., pp. II-23.

II Gombrich-Eribon, op. cit., p. 7I y p. I52. 
N os sitúa primero en un mundo conceptual pero siempre establece una relación con la realidad y el objeto de estudio, ya que todos necesitamos no sólo reflexionar, sino tener respuestas concretas. Primero nos dice, no confundan la realidad con la ilusión, pero más adelante, al explicar la "lógica de la situación", nos abre la posibilidad de crear una hipótesis creíble. Parecería extraño que al destacar lo educativo que puede ser la lectura de los trabajos de Gombrich no se mencione un método específico. Didier Eribon hizo esta pregunta comparándolo con Panofsky, a lo que él respondió: "No necesito uno. Sólo necesito sentido común. Es mi único método... Es muy sencillo: nos hacemos una pregunta y tratamos de descubrir cómo es posible responder a esa pregunta. $\mathrm{H}$ ay muchas preguntas en historia a las cuales no podemos responder, porque no hay indicios. D igo siempre que la historia es como el gruyère: hay muchos agujeros. El talento del historiador consiste precisamente en encontrar preguntas de las cuales cree poder obtener respuestas. Antes de cualquier investigación, hay que decidir. El talento, o podríamos decir el olfato, consiste en sentir lo que es prometedor, el que se vaya a poder descubrir algo. Porque, como yo digo, el resultado es, en muchos casos, 'puede que sí, puede que no'... toda cuestión requiere un método diferente para encontrar la respuesta. Yo digo: 'Si quieres clavar un clavo, utiliza un martillo, si quieres clavar un tornillo, utiliza un destornillador'. $\mathrm{H}$ ay que saber qué método se aplica y para qué cuestión." I2

Si realmente la lectura de $\mathrm{G}$ ombrich educa y forma no es sólo por la forma sencilla en la que siempre creyó al escribir sus ensayos, sino porque creía en la entrega de estafetas, en el relevo creativo, y por esta razón una de las ideas centrales en su trabajo es la de "Tradición" y junto con ella el significado de las convenciones artísticas, eso que un taller entrega a un joven artista para que pueda crear. Esta parte medular de su pensamiento lo llevó a decir: "Todo sistema estético que no tenga nada que decir sobre el lugar de las convenciones en el proceso de creación, parece poco útil para el historiador del arte." ${ }^{13} \mathrm{~A}$ la pregunta de si tenía una filosofía del arte respondió que ella se encontraba en el "Tributo" que le hiciera a I.A. Richards, ${ }^{14}$ y ésta se trata de este tema esencial ya que se titula "La necesidad de Tradición". Es evidente al leer este ensayo que el valor de la tradición dentro de su obra no surgió de la ob-

\footnotetext{
${ }^{12} \mathrm{G}$ ombrich-Eribon, op. cit., pp. I23-I24.

${ }^{13}$ Gombrich, Tributos, op. cit., pp. 182-183.

I4 Gombrich-Eribon, op. cit., p. 75 .
} 
servación de una sociedad que se repite, sino de una necesidad de explicación que encontró en los mecanismos del lenguaje, ya que al igual que Richards creyó en la "teoría que reemplaza a Apolo, como fuente de inspiración poética, por el lenguaje, como guía y maestro". is Partiendo de las teorías del lenguaje de Richards, Gombrich, como solía hacerlo, reordena sus ideas y aplica nuevos conceptos, o más bien bautiza a los mecanismos que describe. Así, dice: "N o le habría ofendido, me parece, que la describiéramos como teoría de retroalimentación, en los términos de la ingeniería moderna. El lenguaje reacciona sobre el hablante." ${ }^{16}$ Y con esto inicia una explicación mucho más completa de lo que nos hubiéramos podido imaginar sobre la "reglas del arte", sobre las convenciones y sobre la tradición. $\mathrm{H}$ aciendo un paralelo constante con los mecanismos del idioma explica que podemos describir el idioma como un grupo de reglas y convenciones, y que por extraño que parezca no es necesario estar consciente de ellas para dominarlo. ${ }^{17}$ Es decir que el lenguaje nos hace creativos sin que estemos conscientes de este milagro; que no adquirimos de pronto este instrumento, aprendemos, como siempre, por tanteo, por retroalimentación. Cometemos errores y los corregimos, pero eso no es todo. De algún modo, después de esta corrección debemos ser capaces de derivar una nueva regla que acabamos de aprender. Si no pudiéramos transferirla a una familia entera de expresiones, jamás progresaríamos..$^{18} 0$ bservando a la gente que hace parodias, imitaciones o falsificaciones, Gombrich concluye: "No sé si al gún psicólogo ha investigado esta capacidad, que yo llamaría de generalización perceptiva, la capacidad no sólo de clasificar familias formales sino también de producir espontáneamente nuevos ejemplos." '19 Tomando en cuenta que en el lenguaje actúan fuerzas prácticas o funcionales diferenciándose de las estéticas y sociales, considera que este proceso de "retroalimentación" que es como lo bautiza G ombrich, utilizando una palabra de la ingeniería, pertenecería a las primeras, ya que el círculo creativo que se establece con el lenguaje es un "círculo virtuoso" de la lengua. Utilizando las teorías darwinistas considera que los mecanismos del lenguaje serían una "creación sin

\footnotetext{
is Gombrich, T ributos, op. cit., p. I84.

${ }^{16}$ Ibidem.

17 Ibidem, p. 185.

I8 I bidem.

19 Ibidem, p. 186.
} 
creador implícita"... "creación sin creador, por decirlo así, creación ciega”. 20 Partiendo de estas reflexiones agrega: "Transferido del vasto panorama de las eras geológicas al angosto escenario de la historia humana, este mecanismo recibe el nombre de tanteo. Fue sobre todo Karl Popper..., quien me convenció de que esta fórmula no sólo aclara el crecimiento de la ciencia, sino la evolución del arte... ni siquiera la llamada imitación de la naturaleza puede lograrse sin el principio de la retroalimentación. Incluso aquí hay un elemento, si no de creación ciega, al menos de tanteo." ${ }^{21}$ Transportando estas ideas al campo del arte dice: "comparé esta idea de retroalimentación con la de self expres sion, que llamé teoría centrífuga, puesto que considera al artista un emisor que transmite sus sentimientos al observador. En su lugar propuse una teoría centrípeta, que hace hincapié en los efectos que tiene la obra en la reacción del propio artista a las convenciones con las que opera". ${ }^{22}$ Como es su costumbre, G ombrich baja de la teoría a los ejemplos y el que da es la creación del Moisés de M iguel Ángel y dice: "Algunos críticos y artistas pestañean cuando escuchan a los historiadores del arte hablar de influencia, como si acusáramos a un genio de robarle las ideas a alguien más; pero todos robamos nuestras ideas porque, como Richards nos recuerda, debemos nuestra lengua a innumerables semejantes que, cuidando los significados, cultivaron el desconocido 'espíritu del H ombre'. Lo que inspiró a M iguel Ángel fue la tradición que vio encarnada con más belleza en el evangelista majestuosamente sentado de D onatello... lo que había heredado era el lenguaje, las convenciones de la escultura occidental para representar figuras de autoridad y poder. ${ }^{23}$ Convertir a la tradición y a las convenciones artísticas, tan desprestigiadas ambas porque obraban en contra de la genialidad del artista, en mecanismos de una lengua, en este caso artística, que en su observación, tanteo y corrección lograban explicar el progreso del arte en un proceso de retroalimentación, fue una hazaña de una mente lúcida como la de G ombrich.\$

\footnotetext{
20 Ibidem, p. 187.

${ }^{21}$ Ibidem.

22 I bidem.

23 I bidem, p. I9I.
} 